\title{
Frequency of infection with Helicobacter pylori isolates of different antimicrobial profiles in children and adolescents: A preliminary study
}

\author{
Grażyna Gościniak ${ }^{1, A, D}$, Monika M. Biernat ${ }^{1, C-E}$, Aldona Bińkowska” ${ }^{1, B}$, Agnieszka Kus ${ }^{1, B, C}$, Barbara Iwańczak2, B \\ ${ }^{1}$ Department of Microbiology, Wroclaw Medical University, Poland \\ ${ }^{2} 2^{\text {nd }}$ Department of Pediatrics, Gastroenterology and Nutrition, Wroclaw Medical University, Poland \\ A - research concept and design; $\mathrm{B}$ - collection and/or assembly of data; $\mathrm{C}$ - data analysis and interpretation; \\ $D$ - writing the article; $E$ - critical revision of the article; $F$ - final approval of article
}

Address for correspondence

Monika M. Biernat

E-mail:mobiernat@gmail.com

\section{Funding sources}

The study was supported by grant for young scientist by Ministry of Science and Higher Education, Poland (No. PBmn 146).

\section{Conflict of interest}

none declared

Received on June 26, 2016

Revised on August 06, 2016

Accepted on December 14, 2016

\begin{abstract}
Background. Helicobacter pylori (H. pylori) infection can occur as a mixed infection caused by several strains of H. pylori.

Objectives. The aim of the study was to determine the frequency of colonization of the gastric mucosa by strains of H. pylori with different susceptibility to antimicrobial agents.

Material and methods. The study was carried out on gastric biopsies taken from 54 previously untreated Polish children and adolescents. Of the 15 positive cultures, from each primary medium, 6 single H. pylori colonies were isolated, making a total of 90 isolates, and the susceptibility to metronidazole (MZ), amoxicillin (AC) and clarithromycin (CH) was determined by E-test method. The presence of the cag $\mathrm{A}$ gene and vac $\mathrm{A}$ alleles (s1, s2, $\mathrm{m1}$, m2) was determined by PCR.

Results. Positive culture for H. pylori was noted in 15/54 (27.7\%) of patients. All H. pylori isolates were susceptible to AC, $27.8 \%$ were resistant to $\mathrm{MZ}$ and $38.9 \%$ to $\mathrm{CH}$. The results showed $7 / 15$ (46.7\%) of children were infected with $H$. pylori strains with antibiotic heteroresistance, resistant to $\mathrm{CH}(5 / 15,33.3 \%)$ and to MZ (2/15, 13.3\%). The cagA + vacA s $1 / \mathrm{m} 2$ combination was predominant genotype among detected H. pylori strains. The isolates possessing different antimicrobial susceptibility profiles in the same patient were identified.
\end{abstract}

Conclusions. Microbiological analyses confirmed the presence of isolates possessing different antimicrobial susceptibility profiles in $47 \%$ of examined children with H. pylori i infection. Different antimicrobial susceptibility profiles of $\mathrm{H}$. pylori isolates detected in the same patient may influence the success of eradication therapy.

Key words: mixed infections, resistance, genotypes

DOI

$10.17219 /$ acem/67716

Copyright

Copyright by Author(s)

This is an article distributed under the terms of the

Creative Commons Attribution Non-Commercial License

(http://creativecommons.org/licenses/by-nc-nd/4.0/) 
Helicobacter pylori (H. pylori) infections affect more than half of the global population. Most infected people live in developing countries, where the infection rate can be as high as $90 \% .{ }^{1}$ In Poland, 58\% are infected and the incidence of infection increases with age, whereas approximately $32 \%$ of children under 18 years of age are infected. ${ }^{2}$ In most cases, the infection is asymptomatic, but it may have a chronic course. Early infection carries a greater risk of developing diseases of the upper gastrointestinal tract, such as peptic ulcers and gastric cancer in the future. ${ }^{1,3}$ Resistance to antibiotics and chemotherapeutics are the primary causes of eradication failure and the high costs of treatment. Furthermore, it is believed that in some individuals a mixed infection with several strains of $H$. pylori with varying antibiotic susceptibility can be present. These strains may be isolated from biopsies taken from different locations in the stomach or the mixed infection can be identified by isolating several strains from one biopsy. However, data on this topic is scarce. ${ }^{4}$ Drug resistance is a worldwide problem. There are some differences in the primary resistance to clarithromycin $(\mathrm{CH})$ and metronidazole (MZ) in different countries..$^{5,6}$ In Poland, the primary and secondary resistance of $H$. pylori strains to $\mathrm{CH}$ is up to 22 and $54 \%$, whereas primary and secondary resistance to MZ is 41 and $68 \%$, respectively. ${ }^{2}$ H. pylori strains are characterized by genetic diversity. It is known that the differences in virulence of these organisms depend on various alleles of the $v a c A$ gene and the presence of pathogenicity island CagA containing cagA gene. The presence of the cagA gene and specific variants of the $v a c A$ gene are related to the level of cytotoxic activity of the pathogen as well as to the clinical consequences of the infection. Determination of certain genotypes can be the basis of the analysis of the diversity of strains in infected individuals. $^{7-9}$ The aim of the study was to determine the frequency of colonization of the gastric mucosa by strains of $H$. pylori with different susceptibility to antimicrobial agents within individual patients.

\section{Material and methods}

The study was conducted on gastric biopsy specimens taken from 54 consecutive children aged $3-18$ years (median 15 years) who were diagnosed and treated in the $2^{\text {nd }}$ Department of Pediatrics, Gastroenterology and Nutrition at the Wroclaw Medical University, Poland during January, February, and March 2014. Patients had not been previously diagnosed and treated for $\mathrm{H}$. pylori infection. Patients who had previously had H. pylori infection or received antibiotics within the last 2 months were excluded from the study. A total of 4 gastric biopsy specimens were taken during endoscopy of the upper gastrointestinal tract from each child: 2 biopsies from the antrum and 2 from the corpus for histopathology and microbiology examinations. The biopsy specimens were evaluated histologically according to the Updated Sydney System. ${ }^{10}$ Biopsies col- lected for microbiological examination were placed immediately after collection in sterile saline $(0.15 \mathrm{M} \mathrm{NaCl})$ and processed within $2 \mathrm{~h}$ at the Department of Microbiology, Wroclaw Medical University. The isolation and identification of strains were performed as described previously. ${ }^{11}$ After obtaining a positive culture, 6 single colonies of $H$. pylori were isolated from each medium (with special attention to differences in the size of colonies) and transferred to new plates with Columbia agar supplemented with $7 \%$ of hemolyzed horse blood which were incubated for 3-4 days in microaerophilic conditions. Of the 15 positive cultures, 6 single H. pylori colonies were isolated from each primary medium, making a total of 90 isolates. Susceptibility of strains to the antibiotics amoxicillin $(\mathrm{AC})$, clarithromycin $(\mathrm{CH})$, and metronidazole (MZ) was determined by gradient diffusion (E-test, BioMerieux) on Mueller-Hinton agar (Oxoid) supplemented with $10 \%$ horse blood under microaerophilic conditions. ${ }^{11}$ The strains were considered resistant to $\mathrm{AC}, \mathrm{CH}$ and $\mathrm{MZ}$ when the minimum inhibitory concentration (MIC) values were $>0.12,>0.5$ and $>8 \mathrm{mg} / \mathrm{mL}$, respectively. ${ }^{11}$ DNA isolation and determination of the cagA gene and $v a c A$ alleles in isolated strains were performed as described elsewhere. ${ }^{12}$ Statistical analysis was performed by $X^{2}$ test with or without Yates' correction. A p-value $<0.05$ was considered significant for all tests. Statistical analyses were done by using STATISTICA v. 10.0 software (StatSoft).

The study was undertaken according to the Declaration of Helsinki. Informed written consent was obtained from all parents and from patients older than 16 years of age.

\section{Results}

On the basis of endoscopy and histopathology findings the 54 examined children were diagnosed with gastric ulcer $(\mathrm{n}=1)$, duodenal ulcer $(\mathrm{n}=2)$, ulcers of the stomach and duodenum $(\mathrm{n}=1)$, chronic gastritis $(\mathrm{n}=34)$, and other gastrointestinal disorders $(\mathrm{n}=16)$ including gastroesophageal reflux disease, celiac disease, lactose intolerance, impaired intestinal absorption with low body weight, irritable bowel syndrome, dyspepsia, Crohn's disease and ulcerative colitis. H. pylori infection was detected in 16/54 (29.6\%) of children and a positive culture for $H$. pylori was noted in $15 / 54(27.7 \%)$ of patients. All tested strains were sensitive to AC $(\mathrm{MIC} \leq 0.016 \mathrm{mg} / \mathrm{L})$. The percentage of H. pylori strains resistant to $\mathrm{MZ}$ was $27.8 \%$ and to $\mathrm{CH}$ $38.9 \%$. One patient was infected with a strain resistant to both $\mathrm{MZ}$ and $\mathrm{CH}$. Strains resistant to $\mathrm{CH}$ showed varying degrees of resistance (MIC, $0.5-256 \mathrm{mg} / \mathrm{L}$ ) and strains resistant to MZ showed a high degree of resistance (MIC, 8-256 mg/L) (Fig. 1). In 8/15 (53.3\%) of patients, H. pylori strains possessed the same antimicrobial susceptibility profiles. H. pylori strains with heteroresistance to MZ and $\mathrm{CH}$ were detected in 7/15 (46.7\%) of children. Infection 
Fig. 1. MIC values for H. pylori isolates obtained from gastric biopsies

EH_S $=$ MTZ_S $=$ MTZ_R $\approx$ CH R

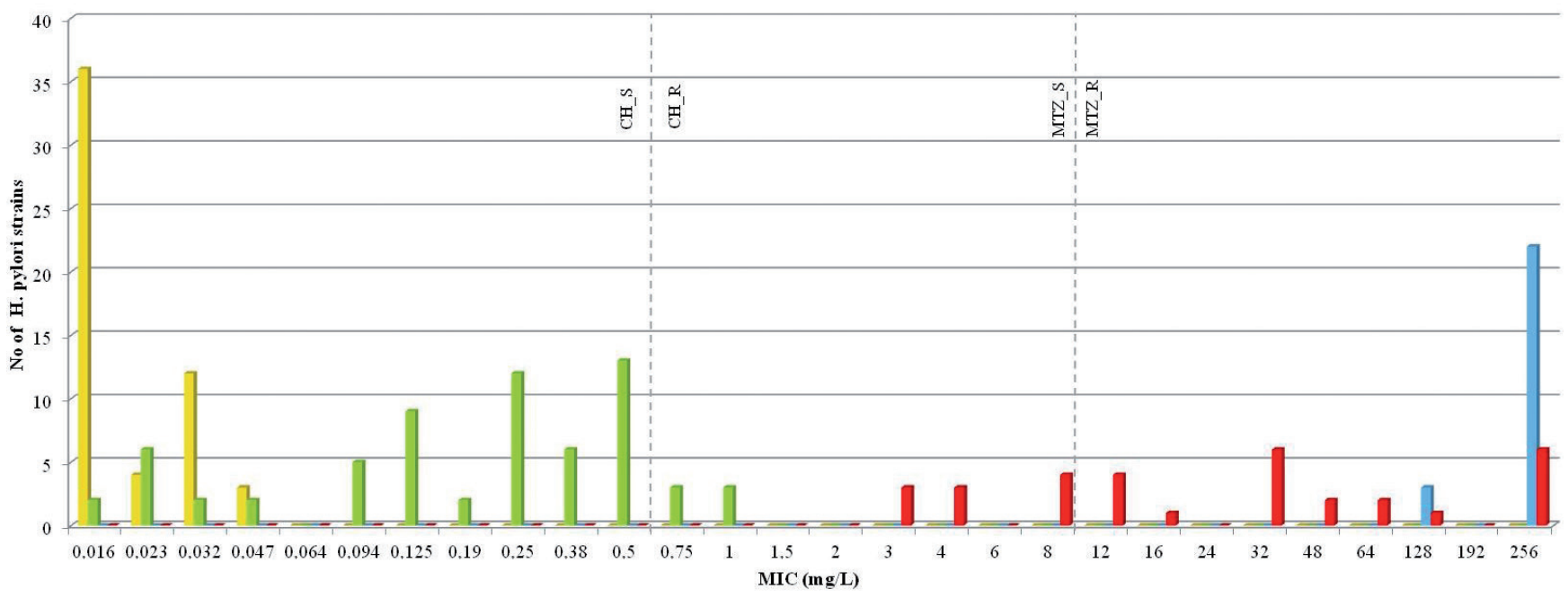

$\mathrm{MZ}$ - metronidazole, $\mathrm{CH}$ - clarithromycin.

with $H$. pylori strains with heteroresistance to $\mathrm{CH}$ and to MZ was demonstrated in 5/15 (33.3\%) and 2/15 (13.3\%) of patients, respectively (Table 1 ). Three patients (no. of patients: $6,8,14$ ) were infected with strains resistant and sensitive to $\mathrm{CH}$, whereas, in 2 children, $H$. pylori strains resistant to $\mathrm{CH}$, but with significantly different $\mathrm{MIC}$ values (32 and 256) were isolated (patient 1 and 3) (Table 2). In 2 children, isolates with different resistance to $\mathrm{CH}$ were identified from corpus biopsies, while in isolates from the antrum differences in susceptibility to antibiotics were not observed. Genetic analyses, determining the presence of the $\operatorname{cag} A$ gene and $v a c A$ alleles $(\mathrm{s} 1, \mathrm{~s} 2, \mathrm{~m} 1, \mathrm{~m} 2)$ were done in 22 selected $H$. pylori isolates, of which 14 strains with heteroresistance profiles were isolated from children with mixed infection, and 8 strains were isolated from patients with infections caused by a single strain. The most common infection was caused by strains with the cagA+
vacA s1/m2 genotype (36.4\%). Correlation between susceptibility profile and bacterial genotypes is present in Table 3. Strains resistant to $M Z$ were $\operatorname{cagA-(66.7\% )}$ and $\operatorname{cag} A+(33.3 \%)$, and the difference was statistically significant $(\mathrm{p}=0.0003)$. In examined children with culture positive for $H$. pylori, the strains possessing the s1 allele and cagA gene were predominant. The $v a c A \mathrm{~s} 2 / \mathrm{m} 2$ genotype was more common in children with chronic gastritis.

\section{Discussion}

The analysis of data from 10 countries in different continents showed a large variation of resistance of $H$. pylori to $\mathrm{CH}$ in children (13.9-84.9\%). ${ }^{13}$ The high percentage of resistance is probably due to the increased use of $\mathrm{CH}$ in the treatment of respiratory infections in children. ${ }^{13} \mathrm{Re}$ -

Table 1. Analysis of antimicrobial susceptibility profile of $H$. pylori strains in examined patients

\begin{tabular}{|c|c|c|c|c|c|}
\hline \multirow{3}{*}{$\begin{array}{l}\mathrm{MZ}+\mathrm{CH} \\
\text { combination }\end{array}$} & \multicolumn{3}{|c|}{ Patients with positive culture for H. pylori $(\mathrm{n}=15)$} & \multirow{3}{*}{$\begin{array}{l}\text { Number of patients } \\
\text { with negative } \\
\text { culture for } H \text {. pylori }\end{array}$} & \multirow{3}{*}{$\begin{array}{l}\text { Number } \\
\text { of examined } \\
\text { children }\end{array}$} \\
\hline & \multirow{2}{*}{$\begin{array}{c}\text { number of patients with strains of } \\
\text { the same antimicrobial susceptibility } \\
\text { profile } \\
\text { MZ }+\mathrm{CH}\end{array}$} & \multicolumn{2}{|c|}{$\begin{array}{c}\text { number of patients with strains of } \\
\text { different antimicrobial susceptibility } \\
\text { profile }\end{array}$} & & \\
\hline & & $\mathrm{MZ}$ & $\mathrm{CH}$ & & \\
\hline $\mathrm{MZ}-\mathrm{S}, \mathrm{CH}-\mathrm{S}$ & $4 / 15(26.7 \%)$ & - & - & & \\
\hline$M Z-R, C H-S$ & 2/15 (13.3\%) & - & - & & \\
\hline$M Z-S, C H-R$ & $2 / 15(13.3 \%)$ & - & - & & \\
\hline $\mathrm{MZ}-\mathrm{R}+\mathrm{S}, \mathrm{CH}-\mathrm{S}$ & - & $2 / 15(13.3 \%)$ & - & & \\
\hline $\mathrm{MZ}-\mathrm{S}, \mathrm{CH}-\mathrm{R}+\mathrm{S}$ & - & - & $3 / 15(20 \%)$ & & \\
\hline$M Z-S, C H-R+R$ & - & - & $1 / 15(6.7 \%)$ & & \\
\hline $\mathrm{MZ}-\mathrm{R}, \mathrm{CH}-\mathrm{R}+\mathrm{R}$ & - & - & 1/15 (6.7\%) & & \\
\hline Total & 8/15 (53.3\%) & $7 / 15$ (46.7\%) & & 39 & 54 \\
\hline
\end{tabular}

$\mathrm{MZ}$ - metronidazole; $\mathrm{CH}$ - clarithromycin; No. - number; $\mathrm{S}$ - sensitive; R - resistant; R+R - heteresistance of isolates isolated from the same patient; $\mathrm{R}+\mathrm{S}-$ isolates resistant and sensitive isolated from the same patient. 
Table 2. Characteristics of H. pylori isolates with different sensitivity to clarithromycin and metronidazole

\begin{tabular}{|c|c|c|c|c|c|c|}
\hline \multirow{2}{*}{ Number of patient } & \multirow{2}{*}{ Source of biopsy } & \multirow{2}{*}{$\begin{array}{l}\text { Number } \\
\text { of isolate }\end{array}$} & \multicolumn{2}{|c|}{$\mathrm{MZ}$} & \multicolumn{2}{|c|}{$\mathrm{CH}$} \\
\hline & & & $\mathrm{MIC}[\mathrm{mg} / \mathrm{L}]$ & $S / R$ & MIC [mg/L] & $S / R$ \\
\hline \multirow[t]{4}{*}{1} & \multirow[t]{4}{*}{ antrum } & 1,2 & 1 & \multirow[t]{4}{*}{ S } & 256 & \multirow[t]{2}{*}{$\mathrm{R}$} \\
\hline & & 3 & 0.25 & & 256 & \\
\hline & & 4,5 & 0.5 & & 32 & $\mathrm{R}$ \\
\hline & & 6 & 1 & & 32 & \\
\hline \multirow[t]{3}{*}{2} & \multirow[t]{3}{*}{ antrum } & $1,2,3$ & 256 & $\mathrm{R}$ & 0.016 & \multirow[t]{3}{*}{ S } \\
\hline & & 4,5 & 0.25 & S & 0.016 & \\
\hline & & 6 & 0.19 & & 0.016 & \\
\hline \multirow[t]{3}{*}{3} & \multirow[t]{3}{*}{ antrum } & 1,2 & 256 & \multirow[t]{3}{*}{$\mathrm{R}$} & 256 & \multirow[t]{2}{*}{$\mathrm{R}$} \\
\hline & & 3 & 128 & & 256 & \\
\hline & & $4,5,6$ & 256 & & 32 & $\mathrm{R}$ \\
\hline \multirow[t]{5}{*}{4} & \multirow[t]{5}{*}{ antrum } & 1,6 & 256 & \multirow[t]{5}{*}{$\mathrm{R}$} & 0.016 & \multirow[t]{5}{*}{$S$} \\
\hline & & 2 & 256 & & 0.023 & \\
\hline & & 3 & 128 & & 0.016 & \\
\hline & & 4 & 128 & & 0.032 & \\
\hline & & 5 & 256 & & 0.032 & \\
\hline \multirow[t]{3}{*}{5} & antrum & 2,3 & 0.25 & S & 4 & $\mathrm{R}$ \\
\hline & & $1,4,5$ & 0.38 & & 3 & \\
\hline & & 6 & 0.19 & & 4 & \\
\hline 6 & corpus & 1 & 0.5 & S & 0.016 & s \\
\hline & & 2,6 & 0.75 & & 48 & $\mathrm{R}$ \\
\hline & & 3 & 0.5 & & 0.016 & S \\
\hline & & 4 & 0.75 & & 64 & $\mathrm{R}$ \\
\hline & & 5 & 0.5 & & 64 & \\
\hline 7 & antrum & 1,5 & 0.125 & S & 8 & $\mathrm{R}$ \\
\hline & & 2,6 & 0.094 & & 8 & \\
\hline & & 3 & 0.094 & & 12 & \\
\hline & & 4 & 0.125 & & 12 & \\
\hline 8 & corpus & 1 & 0.023 & S & 16 & $\mathrm{R}$ \\
\hline & & 2,3 & 0.047 & & 12 & \\
\hline & antrum & $4,5,6$ & 0.023 & $S$ & 0.016 & $S$ \\
\hline 9 & antrum & $1,2,3$ & 0.125 & $S$ & 0.016 & $S$ \\
\hline & & 4 & 0.125 & & 0.023 & \\
\hline & & 5 & 0.094 & & 0.023 & \\
\hline & & 6 & 0.094 & & 0.016 & \\
\hline 10 & antrum & 2 & 0.25 & S & 0.032 & $S$ \\
\hline & & $1,3,4$ & 0.5 & & 0.016 & \\
\hline & & 5,6 & 0.5 & & 0.032 & \\
\hline 11 & antrum & 1 & 256 & $\mathrm{R}$ & 0.023 & $S$ \\
\hline & & 2,3 & 256 & & 0.016 & \\
\hline & & $4,5,6$ & 256 & & 0.032 & \\
\hline 12 & antrum & 1,6 & 0.023 & $S$ & 0.016 & $S$ \\
\hline & & 2,3 & 0.016 & & 0.016 & \\
\hline & & 4,5 & 0.032 & & 0.032 & \\
\hline 13 & antrum & 1,6 & 256 & R & 0.016 & $S$ \\
\hline & & 2 & 0.125 & S & 0.016 & \\
\hline & & 3 & 0.125 & & 0.047 & \\
\hline & & 4,5 & 256 & $\mathrm{R}$ & 0.047 & \\
\hline
\end{tabular}


Table 2. Characteristics of H. pylori isolates with different sensitivity to clarithromycin and metronidazole - cont.

\begin{tabular}{|c|c|c|c|c|c|c|}
\hline \multirow{2}{*}{ No. of patient } & \multirow{2}{*}{ Source of biopsy } & \multirow{2}{*}{$\begin{array}{c}\text { No. } \\
\text { of isolate }\end{array}$} & \multicolumn{2}{|c|}{$\mathrm{MZ}$} & \multicolumn{2}{|c|}{$\mathrm{CH}$} \\
\hline & & & MIC [mg/L] & $\mathrm{S} / \mathrm{R}$ & $\mathrm{MIC}[\mathrm{mg} / \mathrm{L}]$ & S/R \\
\hline \multirow[t]{4}{*}{14} & \multirow[t]{4}{*}{ antrum } & 1 & 0.25 & \multirow[t]{4}{*}{ S } & 96 & $\mathrm{R}$ \\
\hline & & 2,3 & 0.25 & & 0.016 & S \\
\hline & & 4,6 & 0.5 & & 96 & \multirow[t]{2}{*}{$\mathrm{R}$} \\
\hline & & 5 & 0.5 & & 128 & \\
\hline \multirow[t]{4}{*}{15} & \multirow[t]{4}{*}{ antrum } & 1,5 & 0.38 & \multirow[t]{4}{*}{$S$} & 0.016 & \multirow[t]{4}{*}{$\mathrm{S}$} \\
\hline & & 2,6 & 0.25 & & 0.016 & \\
\hline & & 3 & 0.25 & & 0.032 & \\
\hline & & 4 & 0.38 & & 0.032 & \\
\hline
\end{tabular}

MZ - metronidazole; CH - clarithromycin; S - sensitive; R - resistant; No. - number; MIC - minimal inhibitory concentration.

Table 3. Correlation between susceptibility profiles and genotypes among isolated $H$. pylori strains

\begin{tabular}{|c|c|c|c|c|c|c|}
\hline \multirow{2}{*}{ Genotype } & & \multicolumn{3}{|c|}{ Resistant H. pylori strains } & \multirow{2}{*}{$\begin{array}{c}\text { Sensitive H. pylori } \\
\text { strains } \\
\text { no. }(\%)\end{array}$} & \multirow{2}{*}{$\begin{array}{c}\text { Total } \\
\text { no. (\%) }\end{array}$} \\
\hline & & $\begin{array}{c}\mathrm{MZ} \\
\text { no. }(\%)\end{array}$ & $\begin{array}{c}\mathrm{CH} \\
\text { no. }(\%)\end{array}$ & $\begin{array}{c}\mathrm{MZ}+\mathrm{CH} \\
\text { no. }(\%)\end{array}$ & & \\
\hline \multirow[t]{5}{*}{$\operatorname{cag} A(-)$} & $\mathrm{s} 1 / \mathrm{m} 1$ & - & - & - & - & - \\
\hline & $\mathrm{s} 1 / \mathrm{m} 2$ & - & - & $2 / 22(9 \%)$ & - & 2/22(9\%) \\
\hline & $\mathrm{s} 2 / \mathrm{m} 1$ & - & - & - & - & - \\
\hline & $\mathrm{s} 2 / \mathrm{m} 2$ & 2/22 (9\%) & - & - & - & 2/22 (9\%) \\
\hline & total & $2 / 22(9 \%)$ & - & $2 / 22(9 \%)$ & - & 4/22(18\%) \\
\hline \multirow[t]{5}{*}{$\operatorname{cagA}(+)$} & $\mathrm{s} 1 / \mathrm{m} 1$ & $1 / 22(5 \%)$ & 2/22 (9\%) & - & $3 / 22$ (14\%) & 6/22 (27\%) \\
\hline & $\mathrm{s} 1 / \mathrm{m} 2$ & - & 4/22 (18\%) & - & 4/22(18\%) & 8/22 (36\%) \\
\hline & $\mathrm{s} 2 / \mathrm{m} 1$ & - & - & - & - & - \\
\hline & $\mathrm{s} 2 / \mathrm{m} 2$ & $1 / 22(5 \%)$ & $1 / 22(5 \%)$ & - & 2/22 (9\%) & 4/22 (18\%) \\
\hline & total & 2/22(9\%) & $7 / 22$ (32\%) & - & 9/22(41\%) & $18 / 22(82 \%)$ \\
\hline
\end{tabular}

MZ - metronidazole; $\mathrm{CH}$ - clarithromycin; no. - number.

sistance of $H$. pylori strains to $\mathrm{MZ}$ in children showed an even wider range (7.4-95\%), which might result from differences in the frequency of treatment with $\mathrm{MZ}$ for various infectious diseases. ${ }^{13}$ In European children the percentage of strains resistant to $\mathrm{CH}$ is higher (> 30\%) than in adults $(17.5 \%)$, whereas the percentage of strains resistant to $\mathrm{MZ}$ is lower (25.7\%). ${ }^{14}$ This study showed a high prevalence of strains resistant to both $\mathrm{MZ}$ and $\mathrm{CH}$. The resistance to $\mathrm{CH}$ was higher $(38.9 \%)$ than the previously reported resistance to this drug observed in children in Poland (9-29\%), and the resistance to MZ (27.8\%) was located in the middle of the range (16-43\%). ${ }^{2} \mathrm{H}$. pylori strains resistant to $\mathrm{CH}$ showed a wide range of $\mathrm{MIC}$; in the strains resistant to $\mathrm{MZ}$, the MIC values were very high (192-256 mg/L). In our study, all strains of $H$. pylori were susceptible to amoxicillin. These results are similar to other reports. ${ }^{2,5,13}$ Primary resistance to amoxicillin is very rare $(0-2 \%)$; however, in some countries, strains resistant to AC have been detected. ${ }^{2,5,13}$
Gastric mucosa can be colonized with single or multiple strains of $H$. pylori. Furthermore, this colonization may lead to the presence of many sub-populations of $H$. pylori, as the result of genetic mutation or recombination. ${ }^{15} \mathrm{Ge}$ netic exchange of genes between different strains may contribute to the emergence of more virulent strains. It is believed that $H$. pylori undergoes a recombination with heterologous strains much more frequently than is the case with other bacterial species. ${ }^{16}$ In addition, during exposure to the antibiotics used to treat other infections, multiresistant phenotypes of $H$. pylori may occur, which is probably associated with the instability of the genomic DNA of the pathogen as well as with the acquisition of another strain. ${ }^{17}$ The presence of $H$. pylori infections with mixed strains confirmed with genetic analyses varies from 0 to $85 \%$ in different reports. ${ }^{18}$ Studies in European and Western countries have shown that the majority of $H$. pylori strains isolated from different parts of the stomach possessed homogeneous DNA profiles. In contrast, 
the populations of China and Mexico are often infected with mixed strains, genetically heterogeneous, which is associated with a high incidence of infection in the populations. ${ }^{4,16,17}$ In our study, infection with $H$. pylori strains with different sensitivity to the $\mathrm{MZ}$ and $\mathrm{CH}$ was identified in 7 out of 15 children (46.7\%). It can be assumed that such high levels might be the result of a high incidence of H. pylori infection in the Polish population. Our results also showed that clarithromycin-heteroresistance was more frequent in the analyzed strain than the resistance to metronidazole. The common use of clarithromycin in treating respiratory tract infections in Polish children may explain these findings. However, to our knowledge, this is the first study on H. pylori infection with antibioticheteroresistant strains in a Polish population, and more research on this subject is needed in Poland.

The $v a c A$ and cagA genes are used as markers of the genomic diversity of $H$. pylori strains. ${ }^{8,9}$ In East Asia, almost all strains of $H$. pylori are cagAt. In Europe and Africa approximately $60-80 \%$ of the strains are cagA+. ${ }^{19}$ In this study, the presence of the cagA gene was found in $81.8 \%$ of the strains. This result is significantly higher than that observed in other studies in Poland. ${ }^{20}$ Two children infected with heteroresistant $H$. pylori strains showed differences in the presence of the cagA gene. These strains differed in the resistance to MZ; those sensitive to MZ were cagA+, whereas the strains resistant to $M Z$ were $c a g A-$, suggesting an infection in a single patient with different strains. Among the $H$. pylori isolates with heteroresistance isolated from the same patient, the presence of different genotypes, related to the presence of the cagA gene, was detected. It appears that isolates with varying resistance and with different genotypes came from a mixed $H$. pylori infection. However, in the remaining 5 children, the isolates with a different resistance and with the same genotype probably came from a single strain infection. It may be that in these patients, the initially susceptible strains acquired resistance through mutation and genetic recombination, and then later, 2 subpopulations existed together in the gastric mucosa. These results require further analysis and characteristics of the genetic profile of tested strains to confirm or exclude infection with mixed strains of $H$. pylori.

\section{Conclusion}

In conclusion, in $47 \%$ of the examined children infected with $H$. pylori, microbiological analyses confirmed the presence of isolates possessing different antimicrobial susceptibility profiles, and the infection was more commonly caused by strains resistant to $\mathrm{CH}$. Among the isolates with different resistance to $\mathrm{CH}$ and $\mathrm{MZ}$ isolated from the same patient, different genotypes were detected, which may suggest a mixed infection. Different antimicrobial susceptibility profiles of $H$. pylori isolates detected in the same patient may influence the success of eradication therapy.

\section{References}

1. Khalifa MM, Sharaf RR, Aziz RK. Helicobacter pylori: A poor man's gut pathogen? Gut Pathog. 2010;2:2.

2. Laszewicz W, Iwańczak F, Iwańczak B, Task Force of the Polish Society of Gastroenterology. Seroprevalence of Helicobacter pylo$r i$ infection in Polish children and adults depending on socioeconomic status and living conditions. Adv Med Sci. 2014;59:147-150.

3. Salama NR, Hartung ML, Müller A. Life in the human stomach: Persistence strategies of the bacterial pathogen Helicobacter pylori. Nat Rev Microbiol. 2013;11:385-399.

4. Raymond J, Nguyen B, Bergeret M, Dupont C, Kalach N. Heterogeneous susceptibility to metronidazole and clarithromycin of Helicobacter pylori isolates from a single biopsy in adults is confirmed in children. Int J Antimicrob Agents. 2005;26:272-278.

5. De Francesco V, Giorgio F, Hassan C, et al. Worldwide H. pylori antibiotic resistance: A systematic review. J Gastrointestin Liver Dis. 2010;19:409-414.

6. Ghotaslou R, Leylabadlo HE, Asl YM. Prevalence of antibiotic resistance in Helicobacter pylori: A recent literature review. World J Methodol. 2015;5:164-174.

7. Iwanczak B, Laszewicz W, Iwanczak F, et al. Genotypic and clinical differences of seropositive Helicobacter pylori children and adults in the Polish population. J Physiol Pharmacol. 2014;65:801-807.

8. Matos Jl, de Sousa HA, Marcos-Pinto R, Dinis-Ribeiro M. Helicobacter pylori cagA and vacA genotypes and gastric phenotype: A meta-analysis. Eur J Gastroenterol Hepatol. 2013;25:1431-1441.

9. Sgouras DN, Trang TT, Yamaoka Y. Pathogenesis of Helicobacter pylori Infection. Helicobacter. 2015;20(Suppl 1):8-16.

10. Dixon MF, Genta RM, Yardley JH, et al. Classification and grading of gastritis. The updated Sydney System. Am J Surg Pathol. 1996;20:1161-1181.

11. Gościniak G, Biernat M, Grabińska J, Bińkowska A, Poniewierka E, Iwańczak B. The antimicrobial susceptibility of Helicobacter pylori strains isolated from children and adults with primary infection in the Lower Silesia Region, Poland. Pol J Microbiol. 2014;63:57-61.

12. Biernat MM, Gościniak G, Iwańczak B. Prevalence of Helicobacter pylori cagA, vacA, iceA, babA2 genotypes in Polish children and adolescents with gastroduodenal disease. Postepy Hig Med Dosw. 2014;68:1015-1021.

13. Megraud F, Coenen S, Versporten A, et al. Helicobacter pylori resistance to antibiotics in Europe and its relationship to antibiotic consumption. Gut. 2013;62:34-42.

14. Seo JH, Woo HO, Youn HS, Rhee KH. Antibiotics resistance of Helicobacter pylori and treatment modalities in children with $\mathrm{H}$. pylori infection. Korean J Pediatr. 2014;57:67-71.

15. Secka $O$, Antonio M, Berg DE, et al. Mixed infection with cagA positive and cagA negative strains of Helicobacter pylori lowers disease burden in The Gambia. PLoS One. 2011;6(11):e27954.

16. Patra R, Chattopadhyay S, De R, et al. Multiple infection and microdiversity among Helicobacter pylori isolates in a single host in India. PLoS One. 2012;7(8):e43370.

17. Kao CY, Lee AY, Huang AH, et al. Heteroresistance of Helicobacter pylori from the same patient prior to antibiotic treatment. Infect Genet Evol. 2014;23:196-202.

18. Farzi N, Malekian T, Alebouyeh M, Vaziri F, Zali MR. Genotype diversity and quasispecies development of Helicobacter pylori in a single host. Jpn J Infect Dis. 2015;68:176-180.

19. Suzuki R, Shiota S, Yamaoka Y. Molecular epidemiology, population genetics, and pathogenic role of Helicobacter pylori. Infect Genet Evol. 2012;12:203-213.

20. Zalewska-Ziob M, Wiczkowski A, Strzelczyk JK, et al. The prevalence of Helicobacter pylori vacA alleles in patients with chronic gastritis. Adv Clin Exp Med. 2007;16:29-33. 